Infrastructure Asset Management Volume 3 Issue 2

Street work policy in England, UK: insights from stakeholders

Hussain, Enoch, Ruikar, Brien and Gartside
Infrastructure Asset Management, 2016, 3(2), 61-70

http://dx.doi.org/10.1680/jinam.16.00002

Paper 1600002

Received 03/03/2016; accepted 19/04/2016

Published online 13/05/2016

Keywords: infrastructure planning/public policy/roads \& highways

Published with permission by the ICE under the CC-BY license.

(http://creativecommons.org/licenses/by/3.0/) i

\title{
Street work policy in England, UK: insights from stakeholders
}

Rizwana Shaheen Hussain MSc, Cert Eng

Research Engineer, School of Civil and Building Engineering,

Loughborough University, Loughborough, UK (corresponding author: rizwana.hussain@derby.gov.uk)

Marcus Enoch BEng (Hons), MSc (Eng), PhD, MCILT, FHEA, FRGS Senior Lecturer in Transport Studies, School of Civil and Building

Engineering, Loughborough University, Loughborough, UK
Kirti Ruikar BArch, MSc, EngD, FHEA

Senior Lecturer in Construction Management, School of Civil and Building Engineering, Loughborough University, Loughborough, UK

Nigel Brien LLB

Network Management Group Manager, Communities and Place, Derby City Council, Derby, UK

David Gartside

Head of Traffic and Transportation, Communities and Place, Derby City

Council, Derby, UK

Roadworks and street works can be highly disruptive, expensive and deleterious to highway structures and infrastructure planning, yet these activities must take place if modern societies are to continue to function. In helping to strike this balance, this study investigates the public policy landscape of highway excavation management in England, UK. Semi-structured interviews with industry stakeholders highlighted the complexity of the industry and revealed that a number of issues compromise effective management. Principal problems included street authorities failing to take enough ownership of the coordination process, highway legislation not encouraging joint working due to inherent challenges arising from reinstatement guarantees and entrenched attitudes and adversarial practices in the construction industry encouraging silo working. Key recommendations include amending highway legislation to support and recognise multiagency working and street authorities undertaking reinstatements on behalf of undertakers, thus helping to reduce fragmentation and discharge undertakers of onerous guarantees that contribute to silo working.

\section{Introduction}

An estimated 1.5 million utility excavation works (street works) with a direct construction cost of around $£ 1.5$ billion were estimated to occur in the UK annually in 2008 by Parker (2008). The Asphalt Industry Alliance (AIA, 2013) estimated 1.9 million excavations in 2014, increasing to $2 \cdot 2$ million in 2015 . Unsurprisingly, the volume of street works in urban areas is considered to have a negative impact on the road network, causing disruption and premature deterioration (House of Commons, 2011), compromise the street scene (Goodwin, 2005; House of Commons, 2011) and increase significantly social, economic and environmental costs (Jordan et al., 2009; Parker, 2008). The social costs of utility works are estimated to be around $£ 5 \cdot 5$ billion annually, of which $£ 5 \cdot 1$ billion is road user delays alone (McMahon et al., 2005). Comparative figures for highway works (roadworks) are not readily available but are likely to be similarly significant. Such impacts, coupled with yearly increases in excavation activity (Goodwin, 2005) warrant better highway management to reduce highway excavations and their associated impacts. Under the New Roads and Street Works Act 1991 (1991) 'roadworks' are undertaken by highway authorities (HAs) to maintain, rehabilitate and reconstruct highways. 'Street works' are undertaken to install, inspect, maintain, repair or replace utility apparatus in the highway by utility companies. However, for the purpose of this paper, street works will be used to represent both terms given that the public are affected in the same way.

This paper aims to provide the sector's views about street work performance in order to identify where improvements can be made. The paper comprises a literature review providing a state of the art of street work management, an outline of the methods used to perform this study, findings from the study, a discussion and conclusions with recommendations to help improve the management of street works.

\section{Literature review}

Conventionally, utility apparatus is housed underground in modern densely populated urban cities in the UK, USA, China and Japan (Jaw and Hashim, 2013). In order to manage street work activity, technologically and policy-based approaches are typically used (Wilde et al., 2003).

\section{Technologically based approaches}

Open-cut excavations, also known as trenching, have been in operation for around 200 years. Trenching entails cutting and excavating the ground to place utility apparatus underground (Asphalt Industry Alliance, 2013). Trenching is considered disruptive and expensive and having high social costs (Lepert and Brillet, 2009). An alternative to trenching is the use of trenchless technologies, necessitating little or no use of open-cut trenching. Trenchless methods include, among others, horizontal directional drilling, microtunnelling, pipe jacking, auger boring, pipe bursting and robotic spot repairs, which are being used extensively internationally. Trenchless technologies can require greater capital outlay than open-cut methods and thus discourage wider take-up (Ariaratnam et al., 2014; Shukla and Karki, 2013). Utility assets can also be stored in tunnel systems known interchangeably as multiutility tunnels, utility corridors and pipe subways. These tunnels can house single or multiple utilities within purpose-built enclosures constructed for human entry; examples can be found in 
London, Barcelona, Paris, Athens and Tokyo (Canto-Parello et al., 2009; URS, 2009). Tunnels negate the need to trench the highway but are associated with relatively high initial capital investment and long-term maintenance costs, making them unattractive propositions for extensive use (Hunt et al., 2014).

\section{Policy-based approaches}

While street work policy has received relatively limited attention in literature (Tseng et al., 2011), in practice, several schemes exist around the world. For example permit schemes in the UK, Singapore and New York enable regulatory authorities to issue permits for works in the highway (Transport Research Laboratory, 2012). Further, lane rental schemes in London and Sydney enable HAs to rent out highway lanes for specified periods (City of Sydney, 2014; Department for Transport, 2012).

Examples of localised street works policy restrictions include the following.

- One-for-one lane replacement - Work promoters in Singapore are required to provide a temporary lane for any lane lost to street works (Land Transport Authority, 2014).

- Work embargo - Any works involving a road closure are generally restricted to a Sunday in Sydney. Singapore prohibits peak hour working and Hong Kong prohibits works between 7 a.m. and 7 p.m. daily (City of Sydney, 2014; Land Transport Authority, 2014; Transport Research Laboratory, 2012).

The literature review has established techniques used to manage street works; however, a knowledge gap exists about stakeholders' views of street work policy.

\section{Method}

This study was undertaken through conducting 28 semi-structured interviews, whereby interviewees were given the flexibility to guide and expand discussions within set parameters (Bryman, 1988). Interviews were conducted in two stages. Stage 1 comprised exploratory interviews focused around the following discussion themes

(a) performance of street work management system

(b) factors affecting street work management

(c) the future of the street work industry.

Participant selection was initially targeted by using 'snowball sampling' initiated by the Derby City Council as the sponsoring organisation. Subsequently, 'purposive sampling' was used to identify experts. Stage 1 involved 18 traffic management experts from various government agencies and utility companies as well as general managers. 'Experts' were considered as those with interpretative and technical process orientated knowledge (Miles and Huberman, 1994).

Stage 1 interviews provided a developed understanding, which meant more defined questions could be asked in stage 2 as detailed in Table 1. Here, ten interviews were undertaken comprising government, regulatory and business/public representatives. Purposive sampling was adopted to target appropriate expertise from local authorities and the regulator (Flick, 2014). Expert knowledge was not sought from business/public interviewees, as this was not considered necessary. Table 2 provides a breakdown of the interviewees.

Interview findings from both stages were analysed by using a thematic analysis approach involving an iterative process of reading, annotating and coding of data. Commonly occurring themes were labelled and were then analysed, compared and contrasted (Braun and Clarke, 2006). Interview findings were subsequently blended with literature to place them in the context of existing knowledge and provide a comprehensive study.

Theme

Question

Design of overall

process

What is your understanding of the process of managing street works?

Who are your stakeholders and what challenges does their management present?

Do you work with others and how does this influence what you do?

Performance How do you see the street work process performing generally?

What is the current method for measuring street work performance?

Does any incentives/penalties framework exist in your sector?

Context

What are the main issues, constraints and difficulties facing your stakeholders when faced with street works?

What are the issues, constraints and difficulties of your organisation in the utility sector?

What do you consider is working well in street work management?

Future

What current trends are likely to influence the future of street works, and what will their impacts be?

What are the future challenges and opportunities for the roadwork and street work sector?

What recommendations would you make to improve the sector? 
Infrastructure Asset Management

Volume 3 Issue 2
Street work policy in England, UK:

insights from stakeholders

Hussain, Enoch, Ruikar, Brien and Gartside

\begin{tabular}{|c|c|c|c|c|}
\hline \multirow[t]{2}{*}{ Group } & \multirow[t]{2}{*}{ Subgroup } & \multirow[t]{2}{*}{$\begin{array}{l}\text { Interviewee } \\
\text { codes }\end{array}$} & \multicolumn{2}{|c|}{$\begin{array}{l}\text { Intervien } \\
\text { stage }\end{array}$} \\
\hline & & & 1 & 2 \\
\hline \multirow[t]{2}{*}{ Government } & Central & NG1, NG2 & $\checkmark$ & \\
\hline & Local & $\begin{array}{c}\text { LA2 } \\
\text { LA1, LA3-LA5 }\end{array}$ & $\checkmark$ & \\
\hline \multirow{7}{*}{$\begin{array}{l}\text { Regulator } \\
\text { Utility }\end{array}$} & & $\mathrm{R} 1, \mathrm{R} 2$ & & $\checkmark$ \\
\hline & Electric & UE1-UE3 & $\checkmark$ & \\
\hline & Water & UW1-UW4 & $\checkmark$ & \\
\hline & Gas & UG1-UG3 & $\checkmark$ & \\
\hline & Telecoms & UT1, UT2 & $\checkmark$ & \\
\hline & Miscellaneous & UM1, UM2 & $\checkmark$ & \\
\hline & $\begin{array}{l}\text { Industry } \\
\text { representative }\end{array}$ & UR1 & $\checkmark$ & \\
\hline \multirow{2}{*}{$\begin{array}{l}\text { Business and } \\
\text { public }\end{array}$} & Business & B1, B2 & & $\checkmark$ \\
\hline & Public & P1, P2 & & $\checkmark$ \\
\hline
\end{tabular}

Table 2. Breakdown of interviewees and codes

\section{Findings and discussion}

This section discusses the interview findings and seeks to corroborate them against existing literature where available. It begins with describing the key players to aid understanding of the industry. Subsequently, the interview findings are split into the following themes: performance of street work management processes; factors affecting street work management and future challenges and opportunities; and further subthemes. To guide the reader, the structure of the analysis is provided in Table 3.

\section{Key actors}

This section identifies the key actors involved in the street work management industry in England.

- 'Street authorities' (SAs) are part of a council authority and have a statutory duty to manage and coordinate roadwork and street work activity on their road network.

- HAs are part of a council authority with a statutory duty to repair and maintain the fabric and structure of their highways.

- 'Statutory undertakers' (SUs) are those involved with the execution of works related to utility apparatus. They have a statutory duty to make efforts 'to co-operate with the street authority and other undertakers' to assist with the execution of street works (New Roads and Street Works Act 1991, 1991).

- 'Regulators' typically refers to financial regulators in this study who closely monitor the monopoly utility industries of water, electric and gas. Multiple regulators monitor other industry activities and also the telecoms industry.

- The 'construction industry' refers to the network of contractors and subcontractors that the utility industry relies on to deliver their physical works.

- The 'general public' are consumers of utility services and users of the highway.

\section{Performance of street work management processes}

This section discusses the performance of street work management systems as identified by the interviewees. Findings have been categorised into three main areas of performance, namely network management performance, process performance and construction performance. In order to rationalise interviewee comments, discussions have been split into a number of construction
Themes

4.2 Performance of street work management

Subthemes

4.2.1 Network management

End user satisfaction

4.2.2 Process performance

Quality

Functionality

\subsubsection{Construction \\ performance}

Efficiency

Quality

Costs

\subsection{Factors affecting street works}

4.3.1 Permit schemes

4.3.2 Regulatory structure

Regulation and timescales

Conflict in industry and

highway regulations

Commercial sensitivity in

the telecoms industry

\subsubsection{Industry standards}

Highway reinstatement

standards

HA as guarantor

4.3.4 Working relationships

$\begin{array}{ll}\begin{array}{l}\text { 4.4 Practical } \\ \text { coordination barriers }\end{array} & \begin{array}{c}\text { 4.5 Future challenges } \\ \text { and opportunities }\end{array} \\ \begin{array}{ll}\text { 4.4.1 Scheduling } \\ \text { constraints }\end{array} & \begin{array}{l}\text { 4.5.1 Asset } \\ \text { management } \\ \text { 4.4.2 Physical }\end{array} \\ \text { constraints } & \text { 4.5.2 Silo working } \\ \end{array}$


Infrastructure Asset Management

Volume 3 Issue 2
Street work policy in England, UK:

insights from stakeholders

Hussain, Enoch, Ruikar, Brien and Gartside performance indicators (Chan and Chan, 2004) and adapted accordingly as follows

- quality - the degree to which a street work system or process satisfies the user's needs

- functionality - the degree to which a street works system or process fulfils its intended function

- efficiency - the minimal degree to which a system or process expends time and effort

- cost - the degree to which street work activity provides value for money

- end user satisfaction - the level of satisfaction of those who ultimately experience street work operations or systems

\section{Network management}

Network management performance is concerned with the overground impacts of street work activity, and, therefore, the feedback focused on public impact.

\section{End user satisfaction}

Satisfaction levels were low because communication about street works, particularly those directly affecting road users and businesses, was considered unsatisfactory (R1, R2, P1, P2, B1, B2). It was felt that 'utilities should be held to account' for the negative social and financial impact they had (B1). Businesses felt that street works were damaging, and, despite being significantly affected, they had little influence on street work operations. Wong et al. (2012) stressed that limited communication with the public about construction projects can result in a negative image of companies executing works, which should be avoided.

\section{Process performance}

Process performance is concerned with the operational element of street works and focuses mainly on the interactions of SAs and SUs. The interviewees generally discussed the quality and functionality of the processes and collaborative/partnership working. Collaborative working within this context means coordinated multiagency working.

\section{Quality}

The undertakers felt that SAs compromised the effective management of street works by failing to take ownership of the coordination process and lacking the motivation to drive it, despite this being their legal duty (UG1, UW2). Interviewee UG1 stated, 'collaboration doesn't happen unless local authorities make it happen'. Interviewee NG2, a government agency, asserted the SAs' role: 'it is incumbent on local authorities to coordinate and not utilities' The undertakers (UE3, UE2, UW2) expressed a desire to work with others but found it hard to initiate multiutility working because of the logistics of seeking and contacting other undertakers. It is recognised that interorganisational collaboration is intrinsically difficult due to the involvement of multiple actors (Calamel et al., 2012; Johnson et al., 2010). SAs should therefore seek to facilitate collaborative/coordinated working through taking ownership of street work management, providing genuine leadership, vision, strategy and engaging organisational buy-in (Hackman, 1998; Lu et al., 2007; Shea and Guzzo, 1987).

\section{Functionality}

The interviewees alluded to the statutory-prescribed coordination meetings tending to be poorly planned, inefficient and superficial (UM1, UM2). In fact, Engestrom et al. (1997) and Bishop et al. (2009) found that coordinated working in the construction industry tended to be scripted with little genuine collaborative effort. To help address this, SAs should plan and manage coordination meetings diligently to maximise potential multiagency working opportunities. Further, the undertakers felt that SAs were not interested in long-term coordination plans (UM1, UM2, UW2, UW3). UW4 stated, 'Local Authorities don't have very long term plans in comparison with utilities who may plan for 30 years'. Awareness of long-term plans is particularly valuable for authorities with long-term infrastructure management plans known as highway asset management plans. Two key reasons may explain why SAS may not have long-term plans.

- HA budgets - Local government funds are awarded annually and are no longer ring-fenced to highway maintenance; this means shorter maintenance cycles, with no guarantee of spending on highways. Further, austerity cuts have meant reduced budgets and uncertainty over future spending allocations (Lowndes and Pratchett, 2012).

Elections cycles - Frequent elections can cause changing political structures, again promoting short-term objectives (Fenwick et al., 2003).

The allocation of HA budgets and election cycles are factors outside of the control of the SA - changes would be required at the central government level to address these issues in order to have a positive impact on street works.

\section{Construction performance}

This section considers the interviewees' views on construction performance, which focuses on on-site operational issues and factors including silo working, street work quality and financial penalties.

\section{Efficiency}

The interviewees generally accepted that undertakers sought to work individually. Silo working was considered more convenient than integrating work with others, which could undermine individual goals and priorities. LA5 explained, 'utilities are tied into contractors who then sub-contract. Two contractors agreeing to work together does not happen as companies want to maximise their profits'. The construction industry is well documented as an industry symptomatic of fragmentation through its processes, procurement and working practices (Greenwood and $\mathrm{Wu}, 2012$; Xue et al., 2010) and driven by entrenched adversarial relationships where there is no natural desire to work collectively and for the common purpose (Wong et al., 2012). Further, the construction industry workforce was considered a key party in enabling/restraining advancement of street works (LA1, UG1, R1, 
R2). The regulator summarised: 'a lot of control is with the site operatives; it's difficult to change. The age profile of the workforce is high; some have been there since pre-privatisation when costs weren't an issue. A change of mind-set is needed for the old timers' (R2). Ideally, construction firms should seek to modernise culture by managing contractors through performance measurement and management frameworks to evaluate, control and improve performance (Xue et al., 2010). Carefully planned communication and contractor management strategies would help change behaviour and culture.

\section{Quality}

The quality of street work standards was considered as being driven down by SAs who were seeking to minimise street works durations: 'operatives may spend less time on the quality of the work to speed things up, which in the long run is not good' (LA3). Indeed the HA and SA can be considered as having 'adversarial duties', insofar as the HA's priority is highway maintenance, which operationally disturbs the flow of traffic and therefore conflicts with the SAs' network management duty. Therefore, in seeking to manage its duty, SAs may cause undertakers to accelerate works, potentially causing substandard works (notwithstanding prescribed standards), which could undermine structural life and the HA's statutory duty. The local authority must therefore be mindful of both duties and balance network management with high-quality highway structures.

\section{Costs}

The undertakers felt that SAs were using the New Roads and Street Works Act 1991 (1991) to penalise undertakers unnecessarily financially through section 74 (overstay) charges and fixed penalty notices (UW1, UG1, UW2, UW3, UW4, UR1). Interviewee UW2 felt that the utility sector was being used to substitute local authority austerity cuts, with UW4 remarking that 'street works are seen as a cash cow'. The regulator supported the undertakers' concerns: 'utilities feel that they can get penalties easily. They [SA] see it as an opportunity for raising money' (R2). In contrast, LA1 and LA3 expressed unapologetic views suggesting that financial penalties were avoidable and often calculated: 'it may be cheaper for undertakers to receive a fine from us than the logistics of stopping and starting works again on another date.... The consequences of work promoters not following the rules are felt by road users and businesses; the fines are minor compared to the cost of disruption' (LA3). Trust is an important component for interorganisational working; however, an environment where parties feel suspicion and mistrust is unlikely to support a conducive environment for collaborative working (Hackman, 1998; Lu et al., 2007; Patel et al., 2012; Shea and Guzzo, 1987; Shelbourn et al., 2007).

\section{Factors affecting street works}

This section considers those factors that the interviewees considered had an indirect impact on street work management, namely the permit scheme, regulatory structure, industry standards and working relationships.

\section{Permit schemes}

The interviewees had mixed views about the permit scheme, a relatively new approach in England which gives SAs greater ability to control and direct works on the highway; the scheme is chargeable to utility companies and free to HAs. Most of the utility interviewees did not feel that the permit scheme was justified or necessary. Interviewees UE1, UW2, UW3, UW4, UR1, UM1 and UM2 felt that there was nothing within the new enabling legislation (Traffic Management Act 2004, 2004) that was not contained in the New Roads and Street Works Act 1991 (1991), with respondents 6, 7 and 8 stating that the key difference was the ability to charge utilities to undertake works. The utilities were also dissatisfied with the additional work generated by the scheme, creating indirect costs (UW1, UG1, UW2, UW3, UW4, UT2 and UR1). Further, interview UR1 felt that SAs did not exercise parity and that HAs 'got away' with not applying for permits. In contrast, respondents UE1, NG1 and NG2 felt that the permit scheme had come about because of the local authorities' failures to 'coordinate' street works and the utilities' duties to 'cooperate'. Respondent UR1 suggested that both parties should work together to remove the permit scheme.

The regulator acknowledged that SUs had complained that the permit schemes were affecting productivity and were a greater financial burden; however, the regulator saw this as an opportunity to review their processes and make them more efficient (R1). The regulator confirmed: 'the Permit scheme has driven a behaviour change in utility companies; they see it as a big issue. They now pay more attention to planning street works; street works have benefited and so has the general public. They have risen to the challenge'. While there is some acknowledgement of the need for the permit scheme, the SUs were generally opposed to the scheme and did not consider it a value for money exercise; no literature could be found on the empirical evaluation of the permit scheme to corroborate this argument (with the exception of some grey literature).

\section{Regulatory structure}

The undertakers reported allegiance to industry regulations and its associated timescales, conflicts between highway legislation and industry regulation and competitiveness affecting their commitment to street work management. These discussions will be elaborated on further.

\section{Regulation and timescales}

The telecoms industry reported to operating in a 'free market' motivated by fast facilitation of contractual commitments (UT2). Conversely, water, electric and gas undertakers were a part of a monopoly market subject to high levels of financial regulation. Failure to meet regulator deadlines attracted fines and impacted on profits and subsidies awarded. Regulators rewarded undertakers for high customer service and efficient customer facilitation, particularly in terms of faults and new connections (UW1, UG1, UE2). The regulator (R2) reported that 'the regulations constantly require efficiency and demonstrating efficiency... we may not 
fund unless they can demonstrate efficient cost'. The pressure to deliver works in a timely manner meant that the undertakers' business goals often took precedence over street work management. Conflicting goals and timescales can make coordinated working difficult (Patel et al., 2012) further; delaying works to synchronise with others can also lead to negative financial expenses (Johnson et al., 2010). As the speed of service delivery to customers was considered critical by all undertakers, particularly in the case of small works such as connections, SAs should direct coordination efforts on longer duration works, namely 'standard' (3-10 d) and 'major' (over $10 \mathrm{~d}$ ) works.

\section{Conflict in industry regulation and highway regulation}

Some interviewees reported significant 'clashes' between the obligations of the New Roads and Street Works Act 1991 (1991) and respective monopoly industry regulations (UE2, UM1, UG1, UW1, UW2, UW3, UW4, LA1, LA4). Interviewee UE2 summarised: 'neither regulation has any regard for the other'. Interviewee UW1 revealed that sometimes these conflicts compelled them to work against the New Roads and Street Works Act 1991 (1991), which meant that they risked receiving small fines by SAs, as opposed to being 'fined millions' by their regulator. Working in conflict with street work legislation requirements shows an unnecessary compulsion faced by undertakers, which transposes into a lack of trust and openness between parties, which is a significant barrier to effective communication and thus effective joint working (Shelbourn et al., 2007). The regulator (R1 and R2) expressed surprise about perceived conflicts and advised that any specific conflicts brought to their attention would be thoroughly investigated. NG1 and NG2 proposed that permit schemes were solutions for any perceived conflicts.

\section{Commercial sensitivity in the telecoms industry}

As part of operating in a free market, the telecoms industry reported to be operating in a highly competitive industry with high levels of secrecy to protect commercial dealings (UT1, UT2, UR1). Unlike the monopoly industry, there was a distinct hesitation about openly discussing works in the presence of competitors to prevent theft of clients. Like the construction industry, organisations working in the telecoms industry are profit driven where a culture of secrecy is common practice (Bishop et al., 2009). Trust is an important component for nurturing collaborative working (Hashim, 2012; Shelbourn et al., 2007), however, joint working with competitors is regarded as 'adversarial collaboration' (Patel et al., 2012). These issues appear to be barriers in the telecoms sector which restrict sharing of information, which in turn has the effect of reducing joint working opportunities.

\section{Industry standards}

The interviewees felt that highway reinstatement standards and HAs being lead work promoters had a significant impact on street work management. These issues will be looked at further in the next sections.

\section{Highway reinstatement standards}

The reinstatement procedure requires work executors to reinstate and subsequently guarantee reinstatements for a period of at least 2 years (Department of Transport, 2010); this guarantee period was typically referred to as a 'liability' by undertakers (UE2, UW1, UG1, UT1, UW2, UW3, UW4). Issues around the guarantee period centre on the responsibilities of the 'last noticer'. Interviewee UG1 explained: 'Collaboration is more of a problem in terms of sharing liabilities as only one of the two or more utilities can be the lead Notice provider - the lead organisation has to take the most liability and there is reluctance as the company doesn't want to take liability for another utility's carelessness or mistakes'. The undertakers were more willing to work together subject to legal contracts clarifying responsibilities, although this was considered a time-consuming exercise (UT1, UW1). Respondent UE2 stated, 'there is no incentive and even a reluctance to collaborate.... it is too risky'. Indeed section 70 of the New Roads and Street Works Act 1991 (1991) places the entire reinstatement onus on the executor, thus removing the option to share works. It would be beneficial if the New Roads and Street Works Act 1991 (1991) was amended to use terminology that was supportive of and recognised multiagency working. Different working cultures and practices make interorganisational working difficult; thus, parties are motivated by incentives to work together as opposed to risks (Calamel et al., 2012; Patel et al., 2012), which the liability is seen as.

\section{HA as guarantor}

The undertakers proudly cited examples of participation in multiagency working led by HAs as part of their highway maintenance works. In such instances it is highly likely that the HA would be the executor, reinstator and thus guarantor of works (UE1, UG4, UW2, UW7, UW8). The undertakers showed a distinct difference in attitude and enthusiasm to multiagency working once the onus of the reinstatement guarantee had been taken away by the HA (see 'Highway reinstatement standards'). Tapping into the undertakers' willingness to work with HAs, the HA could potentially carry out reinstatements on behalf of the undertakers and discharge them of guarantor obligations at a cost. This would encourage increased multiagency working and encourage consistency in materials and standards across areas. This will be similar to the predecessor legislation, Public Utilities Street Works Act 1950 (1950), where SAs compulsorily undertook all reinstatement works at a cost on behalf of the undertakers. It would be important, however, to take into account previous mistakes to ensure that those issues which led to the original legislation being repealed are not repeated.

\section{Working relationships}

There was a great emphasis on the importance of good working relationships between undertakers and SAs. UW1, UG1, UM1 and UM2 commented that they operated throughout the country with various SAs and each had slightly different approaches to managing street works. Frustratingly, these subtle differences made it difficult for the undertakers to adopt a consistent 
Infrastructure Asset Management

Volume 3 Issue 2
Street work policy in England, UK:

insights from stakeholders

Hussain, Enoch, Ruikar, Brien and Gartside approach. Nevertheless, good working relationships with all local authorities were seen to be vital for successful partnership working as confirmed by Hashim (2012). Respondents UG1, UM1 and UM2 also felt that 'people relationships' were critical. Interviewee UW1 stated, 'some authorities are helpful, others are very prescriptive which is usually not helpful'. The interviewee referred to an SA that would accept communication in only writing, which made it difficult to negotiate changes to planned street works. Formal and informal communication through meetings or discussions, as well as the ability to negotiate, is regarded as 'vital' for collaborative working (Lu et al., 2007). To assist with peer co-operation in negotiation, an argumentationbased negotiation approach could be adopted to facilitate discussion (see the paper by Sierra et al., 1998).

\section{Practical coordination barriers}

The interviewees discussed the working practicalities of joint working. Their views cover two issues, namely scheduling and physical constraints.

\section{Scheduling constraints}

The undertakers considered joint working to be resource intensive (UE1, UG1, UW2). Respondent UE1 stated, 'coordination takes a lot of time, effort and planning'. Utilities in England are profitdriven enterprises; therefore, they can be less inclined to spend time on limited-value-adding activities. Further, entrenched attitudes prevalent in the construction industry towards maximising individual gains and profiteering can make coordinated working 'economically irrational' (Bishop et al., 2009) and therefore reinforce silo working. In addition, disparate timing of works was considered a barrier to multiagency working, '... expectations are unrealistic; coordination involves logistics, gangs and materials all to tie in' (UW3). Similarly, UE2 felt that ' $\ldots$ it would only work with seamless or consecutive working - it doesn't work with differing utilities having different regulator timescales'. An available forum to plan and coordinate works exists through coordination meetings; however, these meetings have previously been described as ineffective (see 'Process performance'-'Quality').

\section{Physical constraints}

Interviewee UW1 stated that 'trench sharing is not easy'. The interviewee referred to guidelines set by the National Joint Utilities Group which specify the sequence and depths of underground apparatus, which were considered a barrier to trench sharing. NG1 and NG2 referred to health and safety risks, with UG1 corroborating: 'it's not usually practically possible for two utilities to work simultaneously... logistics and safety of the job come first; this can make collaboration very difficult'. While trench sharing simultaneously may not always be appropriate due to potential dangers, utilities may be able to reduce risk by working sequentially. This area requires further research to fully understand the risks and likelihood of incident, as well as the impacts of different utilities working together. This can then be advanced into creating a risk scale which could be used by undertakers to determine the differing levels of risk associated with collaborating with other utility industries.

\section{Future challenges and opportunities}

In looking to the future, the interviewees identified asset management and silo working as key issues likely to affect street management.

\section{Asset management}

Key challenges were considered around utilities requiring greater knowledge of the location of their assets (R1, R2). This issue is prolific and is currently being addressed through the Mapping the Underworld project (Rogers and Knight, 2014). Concerns were also expressed about ageing assets; R1 stated, 'buried assets are deteriorating, how do you deal with infrastructure that is over 100 years old?' Despite this concern, the interviewees were optimistic about the rapid development of technologies to help prolong highway and utility asset life (LA1, LA3, LA4, R1, R2). LA4 and LA5 expressed concerns that repeatedly cutting the highway compromised the life of highway infrastructure and questioned whether a 2-year guarantee period was enough or if utilities should be subject to whole life charges. Indeed, a charge structure has been developed for trenching in the highway (Jordan et al., 2009; Latham et al., 2011), which SAs could use as an opportunity and adopt.

\section{Silo working}

Fragmented working among the construction industry was damaging, as it undermined coordinated working (LA1, LA4). Non-local authority interviewees (P1, P2, B1, R1, R2) also desired increased multiagency working to minimise the impact of street works. A way of addressing this could be amending the New Roads and Street Works Act 1991 (1991) to encourage multiagency working by removing the reinstatement onus from the executer. Indeed, the interviewees commented that the New Roads and Street Works Act 1991 (1991) was complex legislation open to interpretation (LA3, LA4, UM1, UE1): 'if legislation was clear and free from ambiguity then it would drive greater collaborative working' (LA4). LA5 also suggested adopting innovative ways of working such as undertakers working from council offices, which would afford undertakers more proactive consideration in street work projects and thus increase multiagency working.

\section{Conclusions}

This research set out to provide an insight into the management of the street work sector and provide the sector's views on its performance to identify where improvements can be made. Principal findings from the research reveals issues on the following.

- Limited ownership of coordination process - Street works are part of a complex industry with direct actors comprising SAs and undertakers, with industry regulators and the construction industry having a significant role and influence, albeit indirectly. Non-local authority interviewees expressed firm 
expectations that SAs should take greater ownership of the management of the coordination of street works. Prescribed coordination meetings were considered ineffective and superficial.

- Recommendation - SAs need to take more ownership and lead by providing strategic vision and direction to enhance street works management.

- Long construction supply chains - The interviewees felt that the construction supply chain played a major role in hindering the effective management and advancement of the street work industry because of its entrenched attitudes, adversarial practices and profiteering culture.

- Recommendation - Undertakers should manage contractors proactively through a performance measurement and management framework to evaluate, control and improve performance.

- Conflicts between industries - There was a perceived conflict between timescales prescribed by the New Roads and Street Works Act 1991 (1991) and industry regulations. In these circumstances, undertakers tended to give greater priority to utility industry timescales as they were driven by financial rewards.

- Recommendation - Any perceived conflicts should be brought to the attention of Highways and Utilities Committee UK to own, investigate and provide remedial measures.

- Onerous reinstatement guarantees - The New Roads and Street Works Act 1991 (1991) was not considered to encourage undertakers to participate in joint working due to the inherent challenges associated with reinstatement guarantees placed on the primary executor of works.

- Recommendation - The New Roads and Street Works Act 1991 (1991) should be amended to use terminology that is supportive of and recognises multiagency working as opposed to placing the single onus on the executer of works.

- The HA as the primary executor - The undertakers showed significantly greater willingness to participate in multiagency working where the HA was the executor and guarantor of works.

- Recommendation - HAs should undertake reinstatement works on behalf of undertakers at a cost and thus discharge undertakers of the guarantee period by becoming the guarantor of the reinstatement. This would also help to encourage consistent reinstatement standards throughout areas.
- Future - Key future concerns were particularly expressed around prolonging the life of highway and utility infrastructure, with technological innovations and the adoption of trenchless technologies and trench charging structures seen as potential opportunities in mitigation. The contemporary prevalent nature of silo working was also seen as an area which would benefit if the New Roads and Street Works Act 1991 (1991) was amended.

- Recommendation - SAs should work with their HAs to adopt policies which champion longer highway structural life such as increasingly adopting trenchless techniques and trench charging.

Overall, street works are expensive for the industry and the society and need to be managed effectively. The significance of this study is that it has identified some of the current problems facing the industry which are impeding the optimal management and efficiency of street work practices. Failure to consider and address these issues will lead to sustained increases in street works, which is an unsustainable scenario, particularly in the current climate of rising street works, decreasing local authority budgets and forecasted population and housing growth. This study contributes to a limited body of literature in street work policy and is novel in that it is the first time a comprehensive study of stakeholder attitudes to street work management has been undertaken.

\section{Acknowledgements}

This research was conducted at the Centre for Innovative and Collaborative Construction Engineering of Loughborough University. The authors would like to thank the Engineering and Physical Sciences Research Council (grant number EP/G037272/1) and the Derby City Council for funding and supporting the research and all the interviewees for their frank contributions.

\section{REFERENCES}

AIA (Asphalt Industry Alliance) (2013) Annual Local Authority Road Maintenance (ALARM) Survey 2013. AIA Press and Information Office, London, UK.

Ariaratnam ST, Luke JS and Michael JK (2014) Current trends in pipe bursting for renewal of underground infrastructure systems in North America. Tunnelling and Underground Space Technology 39: 41-49, http://dx.doi.org/10.1016/j.tust.2012.04.003.

Bishop D, Felstead A, Fuller A et al. (2009) Construction learning: adversarial and collaborative working in the British construction industry. Journal of Education and Work 22(4): 243-260, http://dx.doi.org/10.1080/13639080903290355.

Braun V and Clarke V (2006) Using thematic analysis in psychology. Qualitative Research in Psychology 3(2): 77-101.

Bryman A (1988) Quantity and Quality in Social Research. Routledge, London, UK.

Calamel L, Defelix C, Picq T and Retour D (2012) Interorganisational projects on French innovation clusters: the construction of collaboration. International Journal of Project 
Infrastructure Asset Management

Volume 3 Issue 2
Street work policy in England, UK:

insights from stakeholders

Hussain, Enoch, Ruikar, Brien and Gartside
Management 30(1): 48-59, http://dx.doi.org/10.1016/j. ijproman.2011.03.001.

Canto-Perello J, Curiel-Esparza J and Calvo V (2009) Analysing utility tunnels and highway networks coordination dilemma. Tunnelling and Underground Space Technology 24(2): 185-189, http://dx.doi.org/10.1016/j.tust.2008.07.004.

Chan APC and Chan APL (2004) Key performance indicators for measuring construction success. Benchmarking: an International Journal 11(2): 203-221, http://dx.doi.org/10. 1108/14635770410532624.

City of Sydney (2014) Traffic Management. City of Sydney, Sydney, Australia. See http://www.cityofsydney.nsw.gov.au/ business/business-responsibilities/traffic-management (accessed 01/08/2014).

Department for Transport (2010) New Roads and Street Works Act 1991 Specification for the Reinstatement of Openings in the Highways Code of Practice, 3rd edn. The Stationary Office London, UK.

Department for Transport (2012) New Roads and Street Works Act 1991 Lane Rental Schemes: Guidance to English Highway Authorities. Department for Transport, London, UK.

Engestrom Y, Brown L, Christopher C and Gregory J (1997) Coordination, co-operation, and communication in the courts: expansive transition in legal work. In Mind, Culture and Activity: Seminal Papers from the Laboratory of Comparative Human Cognition (Cole M, Engestrom Y and Vasquez O (eds)). Cambridge University Press, Cambridge, UK, pp. 369-385.

Fenwick J, Cole M and Hutchinson A (2003) Local government: the debate about 'election by thirds'. Representation 39(4): 225-263, http://dx.doi.org/10.1080/00344890308523232.

Flick U (2014) An Introduction to Qualitative Research. Sage, London, UK.

Goodwin P (2005) Utilities' Street Works and the Cost of Congestion. University of the West of England, Bristol, UK.

Greenwood D and Wu S (2012) Establishing the association between collaborative working and construction project performance based upon client and contractor perceptions. Construction Management and Economics 30(4): 299-308, http://dx.doi.org/10.1080/01446193.2012.666801.

Hackman JR (1998) Why teams don't work. Leader to Leader 199(7): 24-31, http://dx.doi.org/10.1002/lt1.40619980709.

Hashim NI (2012) Major challenges in managing multiple project environments (MPE) in Australia's construction industry. Journal of Engineering, Design and Technology 10(1): 72-92, http://dx.doi.org/10.1108/17260531211211890.

House of Commons (2011) Roads: Public Utilities and Street Works. House of Commons, London, UK. Standard Note SN739.

Hunt DVL, Nash D and Rogers CDF (2014) Sustainable utility placement via multi utility tunnels. Tunnelling and Underground Space Technology 39: 15-26, http://dx.doi.org/ 10.1016/j.tust.2012.02.001.

Jaw S and Hashim M (2013) Locational accuracy of underground utility mapping using ground penetrating radar. Tunnelling and
Underground Space Technology 35: 20-29, http://dx.doi.org/ 10.1016/j.tust.2012.11.007.

Johnson P, Hourizi R, Carrigan N and Forbes N (2010) Collaboration and conflict: a framework for large scale collaboration. In International Symposium on Collaborative Technologies and Systems, 17-21 May 2010, Chicago, Illinois, USA, pp. 623-628.

Jordan RW, Ferne BW, McMahon W and Rahman M (2009) A Charge Structure for Trenching in the Highway. Transport Research Laboratory, London, UK. Published Project Report PPR 386.

Land Transport Authority (2014) Road Works. See http://www. onemotoring.com.sg/publish/content/onemotoring/en/ on_the_roads/road_maintenance/road_works.print.html (accessed 03/12/2014).

Latham D, Lancefield R and Elphick R (2011) The involvement and impact of the utilities. In ICE Manual of Highway Design and Management (Walsh ID, Hunter RN, Darrall L et al. (eds)). Institution of Civil Engineers, London, UK, pp. 595-601.

Lepert $P$ and Brillet F (2009) The overall effects of road works on global warming gas emissions. Transportation Research Part $D$ 14(8): 576-584, http://dx.doi.org/10.1016/j.trd.2009.08.002.

Lowndes V and Pratchett L (2012) Local governance under the Coalition government: austerity, localism and the 'Big Society’. Local Government Studies 38(1): 21-40, http://dx. doi.org/10.1080/03003930.2011.642949.

Lu SCY, Elmarghy W, Schuh G and Wilhelm R (2007) A scientific foundation of collaborative engineering. Annals of the CIRPManufacturing Technology 56(2): 605-634, http://dx.doi.org/ 10.1016/j.cirp.2007.10.010.

McMahon W, Burtwell MH and Evans M (2005) Minimising Street Works Disruption: the Real Costs of Street Works to the Utility Industry and Society. UK Water Industry Research, London, UK.

Miles M and Huberman A (1994) Qualitative Data Analysis: an Expanded Sourcebook. Sage, London, UK.

New Roads and Street Works Act 1991 (1991) Elizabeth II. Chapter 22. Her Majesty's Stationery Office, London, UK.

Parker J (2008) Briefing: The real cost of street works. Proceedings of the Institution of Civil Engineers - Transport 161(4): 175-176, http://dx.doi.org/10.1680/tran.2008.161.4.175.

Patel H, Pettitt M and Wilson J (2012) Factors of collaborative working: a framework for a collaboration model. Applied Ergonomics 43(1): 1-26, http://dx.doi.org/10.1016/j.apergo. 2011.04.009.

Public Utilities Act 1950 (1950) Elizabeth II. Her Majesty's Stationery Office, London, UK.

Rogers CDF and Knight MA (2014) Editorial: The evolution of international trenchless technology research coordination and dissemination. Tunnelling and Underground Space Technology 39(1): 1-5, http://dx.doi.org/10.1016/j.tust.2013.11.001.

Shea GP and Guzzo RA (1987) Group effectiveness: what really matters? Sloan Management Review 28(3): 25-31.

Shelbourn M, Bouchlaghem NM, Anumba C and Carrillo P (2007) Planning and implementation of effective collaboration in construction projects. Construction Innovation 7(4): 357-377. 
Sierra C, Jennings NR, Noriega P and Parsons S (1998) A framework for argumentation-based negotiation. In Intelligent Agents IV Agent Theories, Architectures and Languages (Singh MP, Rao A and Wooldridge MJ (eds)). Springer, New York, NY, USA, vol. 1365, pp. 177-192.

Shukla A and Karki H (2013) A review of robotics in onshore oilgas industry. International Conference on Mechatronics and Automation, Takamatsu, Japan, 4-7 August 2013, pp. 1153-1160.

Traffic Management Act 2004 (2004) Elizabeth II. Her Majesty's Stationery Office, London, UK.

Transport Research Laboratory (2012) Interim Report - Reducing Congestion on the Road Network: Plating, Temporary Backfill and Permanent Rapid-cure Reinstatement Solutions. Transport Research Laboratory, London, UK.

Tseng S, Chou C, Ho T, Lin C and Chen T (2011) A spatiotemporal database approach to the management of utility work schedules in transportation projects. Automation in
Construction 20(6): 729-739, http://dx.doi.org/10.1016/j. autcon.2011.01.004.

URS (2009) City of London Decentralised Energy and Pipe Subways Study Baseline Report. URS, London, UK.

Wilde W, Grant C and White G (2003) Controlling and reducing the frequency of Pavement cuts. In Transportation Research Board Annual Conference, Washington, DC, USA, 12-16 January.

Wong K, Kumaraswamy M, Mahesh G and Ng S (2012)

Utilising societal engagement as a vehicle for enhancing the image and sustainability of the construction industry. Sustainable Development 20(3): 222-229, http://dx.doi.org/10.1002/sd.1538.

Xue X, Shen Q and Ren Z (2010) Critical review of collaborative working in construction projects: business environments and human behaviours. Journal of Management in Engineering 26(4): 196-208, http://dx.doi.org/10.1061/(ASCE)ME.19435479.0000025 .

\section{WHAT DO YOU THINK?}

To discuss this paper, please submit up to 500 words to the editor at journals@ice.org.uk. Your contribution will be forwarded to the author(s) for a reply and, if considered appropriate by the editorial panel, will be published as a discussion in a future issue of the journal. 